\title{
Social Behaviors Modulate Bottlenose Dolphins' (Tursiops truncatus) Breathing Rate
}

\author{
Agathe Serres $^{1,2, *}$ and Fabienne Delfour ${ }^{1,2}$ \\ ${ }^{1}$ Parc Astérix, 60128, Plailly, France \\ ${ }^{2}$ Paris 13 University, 99 Avenue Jean Baptiste Clément, 93430, Villetaneuse, France \\ *Corresponding author (Email: agathe.serres11@gmail.com) \\ Citation - Serres, A., \& Delfour, F. (2019). Social behaviors modulate bottlenose dolphins (Tursiops truncatus) \\ breathing rate. Animal Behavior and Cognition, 6(2), 127-140. https://doi.org/10.26451/abc.06.02.04.2019.
}

\begin{abstract}
Breathing frequency is a non-invasive physiological measure that brings valuable information on the bottlenose dolphins' internal state and behaviors. When combined with behavioral observations, it helps to better understand and interpret relevant behaviors. The present study aimed to investigate some basic characteristics of breathing rate in nine dolphins (Tursiops truncatus) (e.g., age and sex effects) and to describe the modulation of the animals' breathing frequency influenced by their simultaneously displayed activity (solitary play, social play, sociosexual and agonistic behaviors) with a focus on social play that is thought to be a potential welfare indicator. Our results showed that young dolphins' breathing frequency was higher than older ones' and this rate was significantly higher when the dolphins were engaged in social play, socio-sexual and agonistic behaviors than when they were not involved in any of these interactions (e.g., resting or other behaviors). These social behaviors might be useful parameters to attribute a stressful or excitement state to the animals and more studies are needed to validate them as dolphin welfare indicators. Moreover, as breathing frequency does not allow to differentiate positive and negative stress in these animals, other physiological parameters should be measured.
\end{abstract}

Keywords - Breathing frequency, Social play, Bottlenose dolphin, Welfare, Respiration rate, Social behavior, Tursiops truncatus

Breathing parameters have been studied in a variety of pinnipeds and cetaceans (fin whale, Balaenoptera physalus, Lafortuna, Jahoda, Azzellino, Saibene, \& Colombini, 2003; killer whales, Orcinus orca, Roos, Wu, \& Miller, 2016; weddell seals, Leptonychotes weddelli, Kooyman, Kerem, Campbell, \& Wright, 1971; bottlenose dolphins, Tursiops truncatus, Williams, Friedl, \& Haun, 1993; Yazdi, Kilian, \& Culik, 1999; harbour porpoise, Phocoena phocoena, Reed et al., 2000; grey seals, Halichoerus grypus, Sparling \& Fedak, 2004; Sparling, Fedak, \& Thompson, 2007). Whereas some studies have focused on breathing and especially on lung mechanisms and the mechanisms of respiration, oxygen consumption and diving capacity of dolphins and other cetaceans (Fahlman et al., 2015; Irving, Scholander, \& Grinnell, 1940), to our knowledge, little is known about the factors that modulate breathing frequency of dolphins in particular. Some studies that have attempted to address this include an investigation of swimming speed on respiration in killer whales (Williams \& Noren, 2009) and an investigation into whether activity of dolphins impacted their breathing frequency (Moderi, 2007), which found no significant effect and concluded that further observations on larger samples were needed. Only this work investigated the effect of the displayed activity and not only the effect of activity intensity parameters (e.g., speed, exercise difficulty). 
Multiple authors suggested the use of parameters of the respiratory system such as breathing rate associated with other parameters to estimate metabolic rates in cetaceans (bottlenose dolphin, Yazdi et al., 1999; gray whale, Eschrichtius robustus, Sumich, 1983, 2001; minke whales, Balaenoptera acutorostrata, Armstrong \& Siegfried, 1991; Blix \& Folkow, 1995; Christiansen, Rasmussen, \& Lusseau, 2014; Folkow \& Blix, 1992; killer whales, Orcinus orca, Williams \& Noren, 2009). A recent study used breathing frequency to estimate the metabolic rate in bottlenose dolphins (Fahlman et al., 2016) with an O2 consumption rate (VO2) prediction to within $2 \%$ before exercise, and overestimated by $12 \%$ postexercise and with the breathing rate increasing with rising VO2. As detailed above, the impact of the activity intensity on breathing frequency has been studied. However, resting and being highly active for instance, do not provide a detailed picture of the various animals' activities, and some differences might be found between behavioral categories. In addition, most studies that aimed to investigate cetaceans' respiration and diving parameters, usually used invasive methods, often involving training of the animals and preventing them from expressing normal behaviors during the ongoing experiments (Irving, Scholander, \& Grinnell, 1941; Wahrenbrock, Maruschak, Elsner, \& Kenney, 1974; Williams et al., 1993; Williams, Haun, \& Friedl, 1999). Using breathing frequency data coupled with behavioral observations, which are both non-invasively measured, allows the animals to behave freely in the pool and to obtain data that is not impacted by a rigid protocol. Even if breathing rate is commonly used in farm animals as an indicator of stress (Bianca, 1958; Brown-Brandl, Nienaber, \& Turner, 1998; Gaughan, Holt, Hahn, Mader, \& Eigenberg, 2000; Srikandakumar \& Johnson, 2004), an increase in breathing rates could occur in both positive and negative contexts and examining breathing as a function of context could thus be valuable.

Bottlenose dolphins live in a fusion-fission society and engage in numerous cooperative and aggressive interactions within their social groups (Mann, Connor, Tyack, \& Whitehead, 2000). They display social behaviors such as petting, synchronous swimming and socio-sexual behaviors (Connor \& Krützen, 2015). Dolphins engage in agonistic interactions with visual and acoustic signals (Overstrom, 1983), and contact behaviors such as hitting and biting (Mann, 2000). Social behaviors in dolphins are thought to be crucial for groups' cohesion, including maintaining social bonds and social dominance between individuals, and are therefore important to study in these animals. Among these behaviors, dolphins engage in various play activities, such as locomotor play, including aerial behaviors, erratic swimming, stranding, and surfing; social play, including cooperating, chasing, and body contacts (Paulos, Trone, \& Kuczaj, 2010), and object play (Kuczaj, Makecha, Trone, Paulos, \& Ramos, 2006).

As respiration patterns are related to different behavioral states (López, Mussi, Miragliuolo, Chiota, \& Valerio, 2000), breathing rate, a non-invasive physiological measure, might contribute to investigate the dolphins' internal state in addition to behavioral observations. An increase in breathing rate could, for example be a sign of stress and the situation perceived by the animal could impact the breathing frequency (Broom \& Johnson, 1993). For instance, Southall et al. (2007) highlighted several parameters such as breathing frequencies to assess the behavioral response of cetaceans when exposed to noise. Finally, Lafortuna et al. (2003) suggested studying fin whale swimming and respiratory patterns together to identify basic behaviors, to better understand them and to aid the conservation of cetacean species.

Play has been put forward as a potential indicator of welfare in dolphins (Serres \& Delfour, 2017). However, the physiological correlates of play on the individuals have not been studied yet. Webster's (2005) principle of triangulation suggests that an understanding of both behavior and physiology is necessary to assess animals' welfare and they need to be used together. Physiological measures such as breathing frequency are thus needed to strengthen the assumption that play but also other social behaviors such as agonistic behaviors, could contribute to evaluate welfare.

The aim of this study was to document dolphins' breathing frequency modulation according to simultaneously displayed behavior. Because bottlenose dolphins are social animals, we mainly focused on social behaviors to determine if they could be more exciting or stressful than other activities. More specifically we investigated how play, agonistic behaviors and socio-sexual behaviors differentially impact the animals' breathing rate. As social play has been put forward as a potential welfare indicator, 
the influence of the intensity of social play activity on the respiratory rate was also studied. Drawing from the above, we critically discuss the ambiguity of breathing rate, which is a parameter to interpret with precautions and whose link with dolphin welfare remains complex.

\section{Methods}

\section{Location, Study Subjects, and Training Schedule}

This study was conducted at the dolphinarium of Parc Asterix (Plailly, France) from January to April 2016. The dolphinarium consisted of one large outdoor and two smaller indoor pools (respectively $3,246 \mathrm{~m}^{3}$ and $2.5 \mathrm{~m}$ at the shallowest point to $4.5 \mathrm{~m}$ at its deepest; $550 \mathrm{~m}^{3}$ and a depth of $2.5 \mathrm{~m}$ ), and the dolphin study group was composed of nine bottlenose dolphins (Tursiops truncatus). The dolphins had free access between the pools at all times. The subjects of this study (Table 1) were two adult males, four adult females (with one pregnant female), two juvenile males (less than 10 years old) and one female calf (less than one year old). The grouping never changed during the study period with all dolphins housed together and all pools accessible. At the time, all the dolphins were subject to the same daily schedule, which included training sessions based on positive reinforcement. In addition, dolphins received free food (i.e., not as reward for exercises) twice a day at 9 am and $5 \mathrm{pm}$. From January through March there were no public presentations (the park was closed), only training, while in April dolphins participated in up to four public presentations per day. During the data collection period, all animals, including the pregnant female F36, were subject to regular health measures such as body temperature, blood samples and veterinary visits, and all of them were thought to be healthy.

Table 1

Bottlenose Dolphins' Individual Features, Breathing Rate Means and Number of Observations for each Displayed Activity

\begin{tabular}{|c|c|c|c|c|c|c|c|c|c|c|}
\hline \multirow[b]{2}{*}{ Individual } & \multirow[b]{2}{*}{ Sex } & \multirow[b]{2}{*}{$\begin{array}{l}\text { Age } \\
\text { (yrs) }\end{array}$} & \multirow[b]{2}{*}{$\begin{array}{l}\text { Size } \\
(\mathbf{m})\end{array}$} & \multirow[b]{2}{*}{$\begin{array}{c}\text { Weight } \\
\text { (kg) }\end{array}$} & \multirow{2}{*}{$\begin{array}{c}\text { Breathing } \\
\text { Rate } \\
\text { mean } \pm \text { SD } \\
(\text { nb/min })\end{array}$} & \multicolumn{5}{|c|}{ Number of Observations for each Activity } \\
\hline & & & & & & Agonistic & $\begin{array}{l}\text { Social } \\
\text { Play }\end{array}$ & Sexual & $\begin{array}{c}\text { Solitary } \\
\text { Play }\end{array}$ & Other \\
\hline F1 & Female & $<1$ & NA & NA & $2.38 \pm 0.07$ & 2 & 11 & 4 & 10 & 35 \\
\hline M4 & Male & 4 & NA & 142 & $2.28 \pm 0.07$ & 3 & 15 & 11 & 6 & 27 \\
\hline M5 & Male & 5 & NA & NA & $2.16 \pm 0.07$ & 2 & 11 & 10 & 5 & 34 \\
\hline F16 & Female & 16 & 2.50 & 224 & $2.02 \pm 0.06$ & 2 & 1 & 0 & 1 & 58 \\
\hline F21 & Female & 21 & 2.38 & NA & $1.94 \pm 0.06$ & 0 & 0 & 0 & 1 & 61 \\
\hline M31 & Male & 31 & NA & 304 & $2.02 \pm 0.08$ & 1 & 1 & 2 & 7 & 51 \\
\hline M34 & Male & 34 & 2.47 & 232 & $1.9 \pm 0.06$ & 2 & 0 & 2 & 9 & 49 \\
\hline F36* & Female & 36 & 2.62 & NA & $2.28 \pm 0.07$ & 1 & 1 & 0 & 7 & 53 \\
\hline F43 & Female & 43 & 2.73 & 243 & $1.84 \pm 0.07$ & 0 & 3 & 0 & 2 & 57 \\
\hline
\end{tabular}

*Pregnant

\section{Data Collection}

Every morning at $9 \mathrm{am}$, for a duration of $5 \mathrm{~min}$, the dolphins' breathing frequencies were recorded from the surface by three experienced dolphin trainers. Trainers were used to work as a team 
around the pools to report every breath by telling the name of the individual who breathed to a colleague who was writing it in a table. At the same time, the occurrence of social play, solitary play, socio-sexual behavior and agonistic interactions of the dolphins (Table 2) were directly observed by an observer placed in front of underwater windows and by the three trainers using focal object sampling (Mann, 1999). Other social and solitary behaviors (e.g., synchronous swimming, swimming alone, floating, rubbing) were categorized as "other behavior." Sixty-two observation sessions lasting $5 \mathrm{~min}$ were achieved during a four month period. Because the protocol required four experienced people to collect physiological and behavioral data, we followed the daily routine record conducted by trainers during $5 \mathrm{~min}$ in the morning. During the recording, all animals had free access to the three pools.

Table 2

\begin{tabular}{ll} 
Description of the Behavioral Categories used by the Observers \\
\hline Behavioral Category & Description \\
\hline Social play & $\begin{array}{l}\text { Any interaction involving at least two individuals, and including behaviors such as } \\
\text { chasing, biting, etc., with a speed and a context enabling to distinguish it from agonistic } \\
\text { interaction. }\end{array}$
\end{tabular}

Solitary play

Any interaction with an object from the environment (human-made object or items present in the pool).

Socio-sexual behavior

Any interaction involving at least two individuals and including behaviors such as sexual rubbing or mounting.

Agonistic behavior

Any interaction involving at least two individuals, and including behaviors such as chasing, biting, etc., with a speed and a context enabling to distinguish it from social play.

Other behaviors

Any other behavior that was not part of above categories, such as swimming alone, synchronous swimming, rubbing with the environment, etc.

The intensity of the social play sequences (Table 3) was described based on an adapted version of Vicino and Marcacci's (2015) scoring system for elephants (Loxodonta africana).

Parc Asterix Welfare committee and the European Inter-parks scientific Committee attended by international marine mammals' experts approved the project.

Table 3

Descriptions of the Social Play Intensities

\begin{tabular}{lll}
\hline Intensity & Play Intensity & Behavioral Description \\
\hline S0 & None & No social play \\
S1 & Mild & $\begin{array}{l}\text { Low speed swimming, few low speed movements, slow rostrum pushing, slow melon } \\
\text { hitting and/or slow biting }\end{array}$ \\
S2 & Moderate & A little bit faster, movements can be connected, dolphins can follow each other \\
S3 & Vigorous & $\begin{array}{l}\text { Fast speed, chasing, U-turn movements, jumping out of the water or turning around each } \\
\text { other rapidly }\end{array}$ \\
S4 & Intense & Very fast speed, fast chasing, jaw clapping, U-turns or jumping above water
\end{tabular}

Note: Adapted from Vicino and Maracci (2015)

\section{Analysis}

All data analysis was performed using $R$ (Rx64 3.2.5, R core team, 2016). The inter-observer reliability between three observers was tested using Intra Class Correlation $(\mathrm{F}=23.4$, ICC $=0.96, p<$ 
.0001). To achieve this test, three observers watched several same videos of this group of dolphins and filled the same table to ensure they were categorizing behaviors in the same way. A linear mixed-effects model (LMM) was conducted with a permutation test applied on the model to analyze the sex and age effects on the dolphins' breathing frequency. The individual identities were included in the model as a random factor. As the data on the size and weight of individuals was not complete, we did not conduct statistical analysis to test their effect on individuals' breathing rate but we discussed it.

Generalized linear mixed-effects models (GLMM) for Poisson distributed data coupled with Wald Chi square tests were used to analyze the breathing frequencies in relation to the dolphins' activity. The response variable was the number of breaths per dolphin per five minutes with all animals combined. The predictor variables (occurrences of social play, solitary play, sexual behavior and agonistic interactions) were transformed into binomial data (presence/absence of those behaviors) for each individual. When a dolphin was engaged in two of the four noted behaviors during the 5 min observation, the data were not included in the analysis. Over-dispersion was tested for each model and a case level random factor was included if the model was over-dispersed. Because young dolphins are known to play more frequently than adults (Paulos et al., 2010) and because breathing frequency decreases with increasing age (Mortola \& Limoges, 2006), these statistical tests were performed twice: once including all the individuals' data and once including only the three young individuals' data to avoid a bias. A GLMM was also used to test the effects of the social play intensity upon breathing frequency. Because the most intense category of social play (very fast speed, fast chasing, jaw clapping, U-turns or jumping; see Table 1) was observed only once during the observations, it was excluded from the analysis.

In these models, the day and the identity of individuals were included as random factors. A sequential Bonferroni correction (Holm, 1979) was applied for all post-hoc tests of the analysis.

\section{Results}

The dolphins' breathing rates averages ranged from 9.2 to 11.9 breaths $/ 5 \mathrm{~min}$ or from 2.2 to 2.3 breaths/minute (Table 1). Out of a total of 558 individual observations (or observations of nine dolphins during 62 sessions), 13 were scored as agonistic behaviors, 42 as social play, 30 asexual behavior, 48 as solitary play and 425 as "other behavior."

\section{Age and Sex}

Dolphins' breathing frequency decreased significantly with age (LMM: $d f=6, p=.022$, Figure 1). There was no significant difference in males'versus females' breathing frequency $(d f=1, p=.732)$.

\section{Breathing Frequency and Play}

In the whole group. The dolphins' breathing frequency was significantly different depending on the activity of the dolphins (GLMM: $\chi^{2}(4)=43.22, p<.001$ ). The dolphins had a significantly higher breathing frequency when they were engaged in social play $\left(\chi^{2}(1)=26.89, p<.001\right)$, or solitary play $\left(\chi^{2}(1)=6.38, p=.011\right)$, during the five minute observation than when they were involved in "other behaviors" (Figure 2A). The dolphins' breathing frequency tended to be higher when engaged in social play $\left(\chi^{2}(1)=3.49, p=.062\right)$ than in solitary play.

In young dolphins. Young dolphins had a significantly higher breathing frequency when they displayed social play $\left(\chi^{2}(1)=22.38, p<.001\right)$ or solitary play $\left(\chi^{2}(1)=6.25, p=.012\right)$ than when they displayed other behaviors (Figure 2B). Their breathing frequency was not significantly different depending on whether they were engaged in social or solitary play $(p=.290)$. 


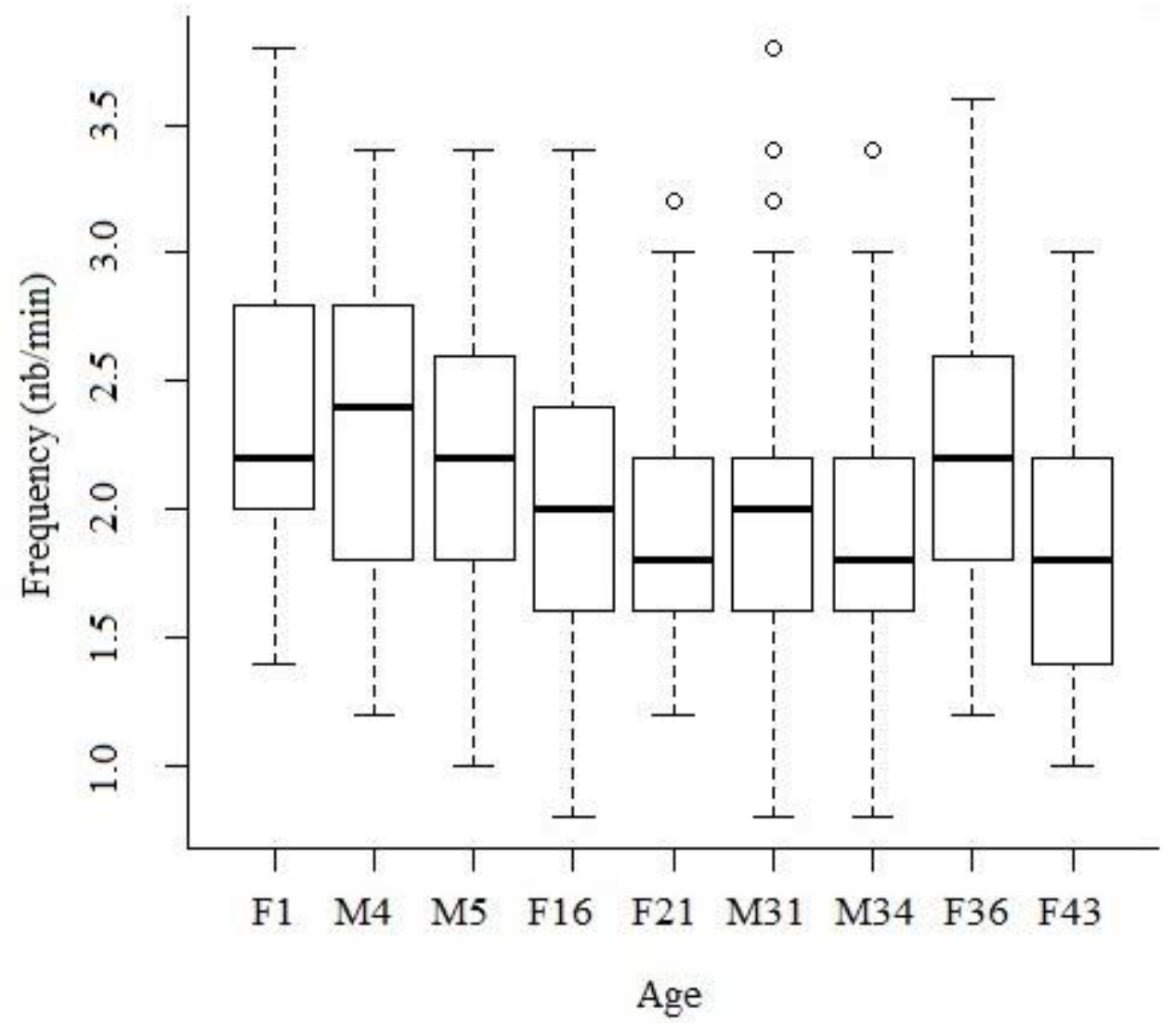

Figure 1. Breathing frequency of bottlenose dolphins in relation to their sex and age, denoted by the letter $(\mathrm{F}=\mathrm{female}, \mathrm{M}=$ male) and digit (years) in the individual identifiers.

\section{Breathing Frequency and Behaviors}

In the whole group. The dolphins had a significantly higher breathing frequency when they were engaged in agonistic interactions or sexual behavior during the five minute observation than when they displayed "other behaviors" (respectively GLMM: $\chi^{2}(1)=12.77, p<.001$; and $\chi^{2}(1)=8.73, p=.003$, Figure 2A). The dolphins' breathing frequency was significantly higher when they were involved in agonistic interactions than in solitary play $\left(\chi^{2}(1)=4.02, p=.045\right)$ but there was no significant difference depending on whether they displayed sexual behaviors or solitary play $(p>.05)$. No significant difference in breathing frequency was observed between the observations during which dolphins were involved in agonistic or sexual behaviors $(p=.191)$.

In young dolphins. Young dolphins had a significantly higher breathing frequency when they displayed agonistic behaviors than when they displayed other behaviors $\left(\chi^{2}(1)=4.72, p=.030\right)$, and their breathing frequency tended to be higher when they were engaged in sexual behaviors than when displaying other behaviors $\left(\chi^{2}(1)=3.62, p=.057\right.$, Figure 2B).

Social play intensity

Breathing frequency significantly increased with the social play intensity $\left(\right.$ GLMM: $\chi^{2}(1)=18.72$, $p<.001$, Figure 3). 
(A)

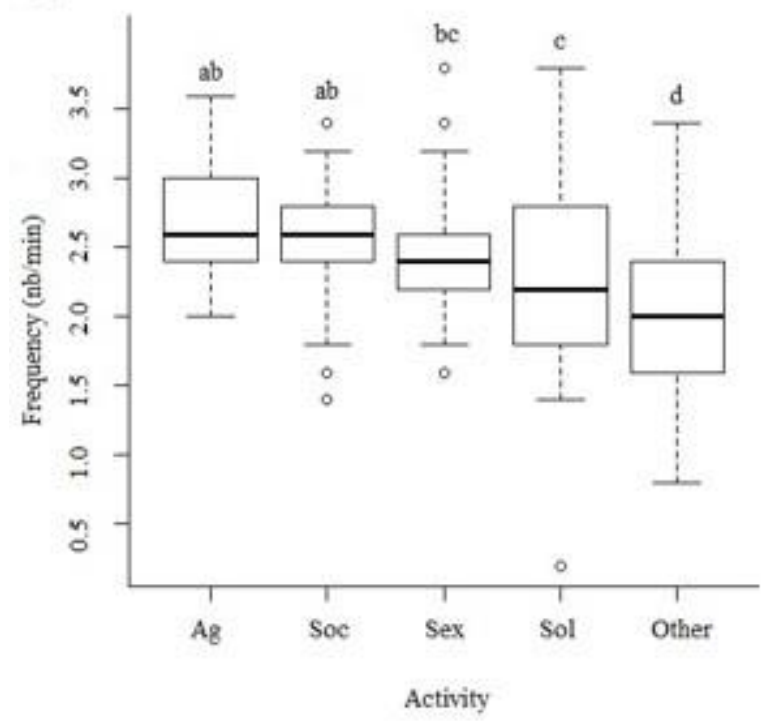

(B)

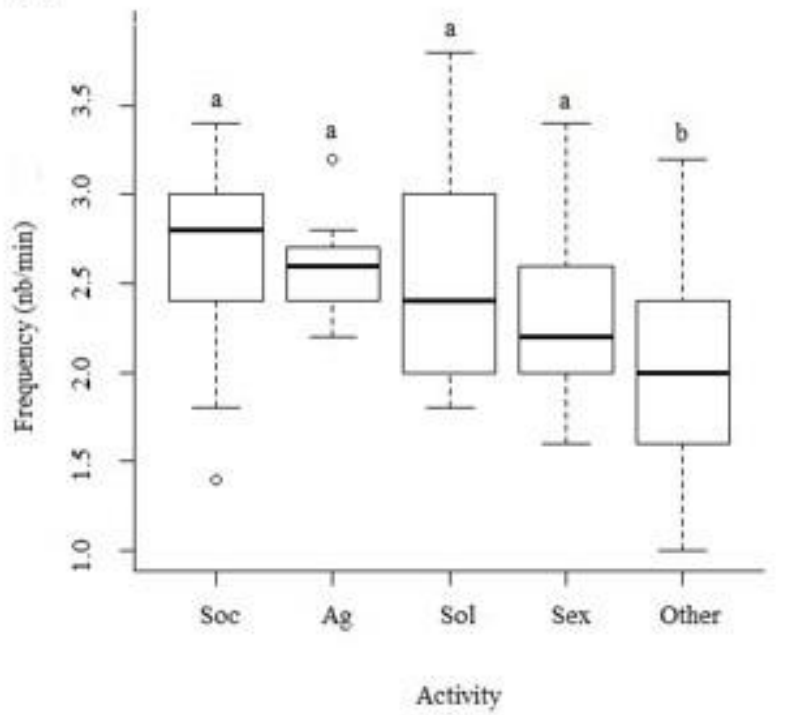

Figure 2. Breathing frequency of bottlenose dolphins in relation to behavioral activity during the five minute observation sessions $(\mathrm{Ag}=$ agonistic behavior, Soc $=$ social play, Sex = sexual behavior, Sol = solitary play, Other $=$ other behaviors $)$, for (A) all dolphins $(n=9)$ and $(\mathbf{B})$ young dolphins only $(n=3)$. Letters denote significant $p$ values or tendencies with sequential Bonferroni correction; different letters indicate a significant difference or a tendency.

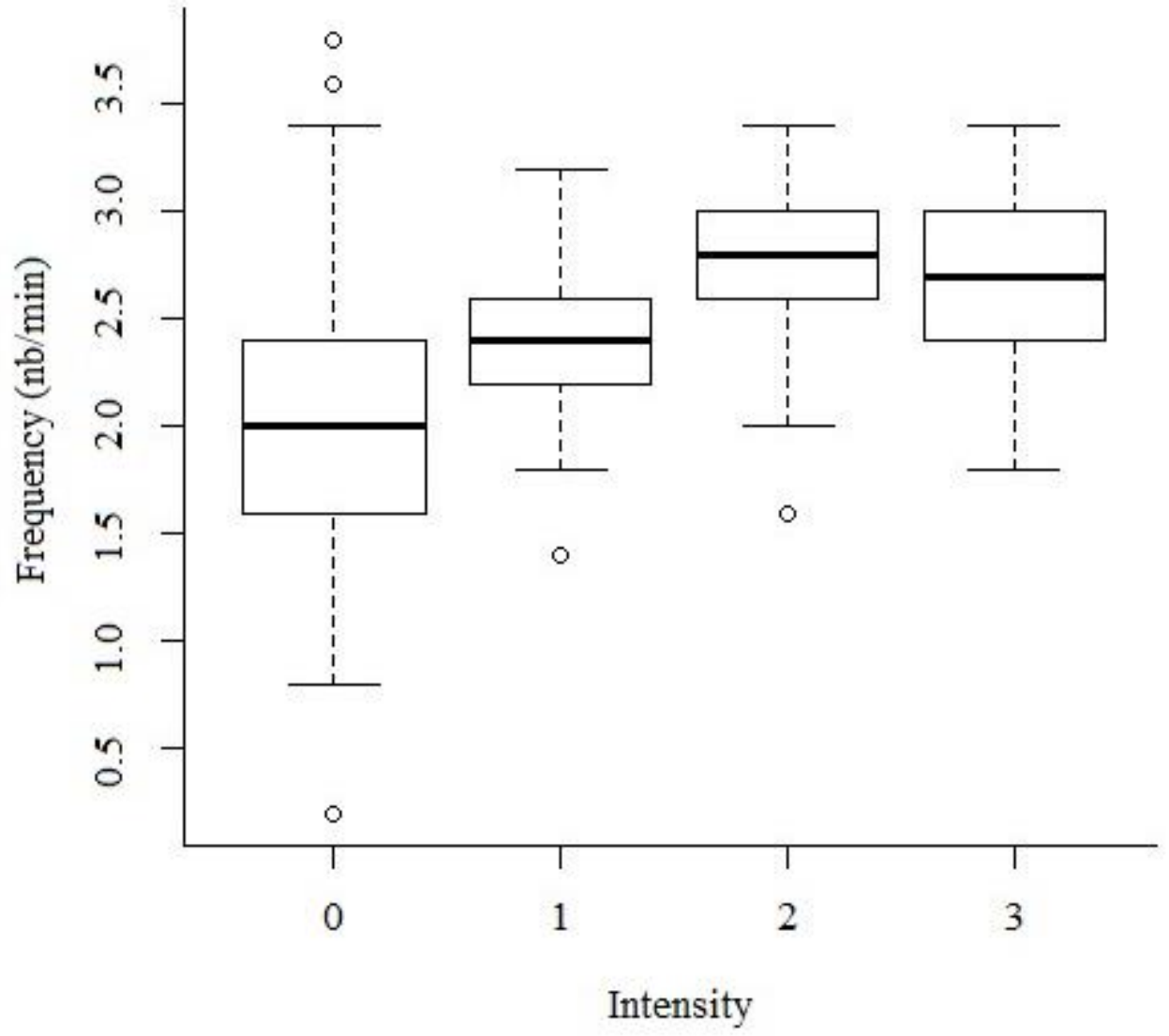

Figure 3. Bottlenose dolphins' breathing frequency according to the intensity of their social play interactions $(0=$ no social play, $1=$ mild, $2=$ moderate, $3=$ vigorous, Table 3 ). 


\section{Discussion}

Individual breathing rates of the nine dolphins ranged from 9.3 to 11.9 breaths $/ 5 \mathrm{~min}$ or from 1.8 to 2.4 breaths/min, with adults' rates ranging from 1.8 to 2 breath/min, juveniles' rates ranging from 2.2 to $2.3 \mathrm{breath} / \mathrm{min}$ and finally, the calf's rate being $2.4 \mathrm{breaths} / \mathrm{min}$. These findings are similar to those of Mortola and Limoges (2006) with an adult captive bottlenose dolphin's breathing rate of 2.3 breaths/min during low speed swimming and a calf's rate of 2.4. In our study, male and female dolphins' breathing rate did not significantly differ. Similar results were found in captive killer whales (Miller, Shapiro, \& Deecke, 2010; Roos et al., 2016) and wild bottlenose dolphins (Nowacek, Wells, \& Solow, 2001). Some bottlenose dolphin populations show sexual size dimorphism (i.e., larger males, Read, Wells, Hohn, \& Scott, 1993), which could explain an intersexual difference in breathing rate. However, this sexual morphological difference did not seem to impact the breathing frequency in this study, probably because it is not that prominent within T. truncatus.

\section{Age and Breathing Rate}

Dolphins' breathing frequency decreased with age. This is congruent with the previous findings about age effect on breathing rate in cetaceans (bottlenose dolphins: Mortola \& Limoges, 2006; beluga whales, Delphinapterus leucas: George \& Noonan, 2014). In addition, wild bottlenose newborn calves, whose breathing rates are identical to captive dolphins', breathe more frequently than their mother (Mann \& Smuts, 1999). This could be explained by the fact that calves improve their diving competence during the second year of life but after three years old, their diving ability does not change much (Moderi, 2007), and by the fact that marine mammal calves' and juveniles' blood has lower oxygen storage than adults (Dolar, Suarez, Ponganis, \& Kooyman,1999; Noren, Iverson, \& Boness, 2005; Noren, Lacave, Wells, \& Williams, 2002; Noren, Williams, Pabst, Mclellan, \& Dearolf, 2001). Myoglobin, for example, is an oxygen storage component and has a long development time (Dolar et al., 1999; Noren et al. 2001; 2005). Muscle oxygen storage ability also increases with age (Noren et al., 2002).

Body size, which is positively correlated with longer dive duration, can also influence diving capacity (Marino, Sol, Torren, \& Lefebvre, 2006; Noren \& Williams, 2000) and younger animals might not reach lower breathing frequencies and thus adult diving capacity until they reach their adult size. It is likely that several factors such as smaller body size and physiological aspects [lower myoglobin and hemoglobin concentration in young compared to adults (Noren, Biedenbach, \& Edwards, 2006)] might cause a belated motor functioning in calves. A study on several odontocete species including bottlenose dolphin showed large body size in odontocetes enables increased aerobic breath-hold capacity because of decreased mass-specific metabolic rates (Noren et al. 2012), mass-specific metabolic rates and relative rates of oxygen utilization in tissues being the highest in the smallest marine mammal species (Williams, Haun, Davis, Fuiman, \& Kohin, 2001). Diving cetaceans could benefit from a big body size inducing higher absolute size of oxygen storages and an advantage regarding relative decrease in mass-specific metabolic rate (Noren \& Williams, 2000). This could also explain the differences in our studies' breathing frequencies as the oldest dolphins are also the heaviest with M31, an adult male being the heaviest and owning the higher mean breathing frequency among adult individuals except the pregnant female. An opposite relationship between body-size and breathing rate was found in captive beluga whales, with smaller adults breathing more frequently than larger ones (George \& Noonan, 2014). However, the lack of weight and size data in our study does not allow us to clearly state their impact on individuals' breathing frequency.

The pregnant female F36 had a higher breathing frequency than the other adults. It might be explained by her weight and her reproductive status during the observations. Female energetic requirements are higher during lactation (Costa, LeBoeuf, Huntley, \& Oritz, 1986; Fedak \& Anderson, 1982) and the increase in drag because of the bigger body shape also increases these energetic needs (Noren, Redfern, \& Edwards, 2011). The energetic cost, especially in terms of oxygen, of swimming when pregnant could be higher than the normal cost of swimming. 


\section{Breathing Frequency and Play}

The dolphins' breathing frequency was higher when they were engaged in social play and solitary play than when they were displaying "other behaviors." And this was also true when analyzing only the young dolphins' breathing frequency. The breathing rate observed when engaged in social play tended to be higher than when engaging in solitary play. A study on wild bottlenose dolphins showed no significant differences in breathing-rate depending on activity (Moderi, 2007). However, this study presents many limitations: the sample size was limited (five animals), the conducted observations focused on certain individuals and some individuals never or rarely engaged in the behaviors that were compared. Moreover, the researchers compared resting behavior to play and foraging behaviors, and whereas most animals had a reasonable number of observations while resting, some were less active than others, so it was impossible to compare their breathing rates between activities as there were very few observations from when they were playing or foraging. Because a higher breathing rate can reflect excitement (Ax, 1953), the difference between social and solitary play seems to reveal that social play could be more exciting for dolphins than solitary play. Social play is a quite complex social behavior requiring social cognitive abilities and involving various emotions that we might not find in solitary play. It is well known that dolphins are highly social animals (Mann et al., 2000), social play could thus be an important component of their life under human care and might be useful to assess welfare.

\section{Breathing Frequency and Social Play Intensity}

An increasing intensity of social play engenders an increase of dolphins' breathing frequency. As play in bottlenose dolphins can be very intense with fast speed swimming (Kuczaj \& Eskelinen, 2014), the speed might increase the breathing frequency (Williams \& Noren, 2009). The swimming metabolism for cetaceans was assessed from swimming speeds and respiration rates (minke whales, Christiansen et al., 2014), a higher rate being linked to a higher swimming metabolism (gray whales, Sumich, 1983) or a physically challenging exercise (bottlenose dolphin, Williams et al., 1993). During social play, cetaceans have been noted to display various play activities (Pace, 2000; Paulos et al., 2010). Some play activities are more spectacular than others, where animals engage in a variety of energetic aerial behaviors (e.g., breaching behavior in bowhead (Balaena mysticetus, Würsig, Dorsey, Richardson, \& Wells, 1989) and right whales (Eubalaena australis, Thomas \& Taber, 1984) calves, aerial activities in bottlenose dolphins (Bel'kovich, Lvanova, Kozarovitasky, Novikova, \& Kharitonov, 1991; Würsig \& Würsig, 1979). As the state of playfulness is thought to be exciting (Spinka, Newberry, \& Bekoff, 2001), this excitement might also increase the animals' breathing frequency (Ax, 1953). However, in bottlenose dolphins, whereas play can be a pleasurable and/or fun behavior, it can also become dangerous (Kuczaj \& Eskelinen, 2014), with intense play fighting bouts evolving into real fights (e.g., display of head-to-head behavior, intense chasing behavior, charges, biting behavior (Connor, Smolker, \& Richards, 1992). The frontier between positive and negative play excitement is thus hard to find and impossible to define with breathing frequencies.

\section{Breathing Frequency and other Social Behaviors}

Play is not the only behavior that caused an increase in breathing rate in our study. The dolphins' breathing frequency was significantly higher when dolphins were engaged in agonistic or socio-sexual behaviors than when engaged in "other behaviors". This was also true when analyzing young dolphins" data alone. Agonistic interactions are known to be stressful (Clark, Cowan, \& Pfeiffer, 2006; St. Aubin \& Dierauf, 2001; Waples \& Gales, 2002), stress could thus increase the breathing frequency of the dolphins (Broom \& Johnson, 1993). Socio-sexual behaviors, which are common in bottlenose dolphins, including male-male sexual interactions and masturbation (Mann, 2006; McBride \& Hebb, 1948; Shane, Wells, \& Würsig, 1986), are often accompanied by a motivation-specific excitement (McBride \& Hebb, 1948, Sauer, 1963), which could explain the higher breathing frequency (Ax, 1953). As social relationships play 
an important role in the lives and well-being of dolphins (Waples \& Gales, 2002) and because of the related excitement state of these two social behaviors and of their impact on the group's social dynamics (Clemente \& Lindsley, 1965), they could be important to investigate further.

During this study, to adapt to the trainers' schedule, the observations were conducted in the morning, after the dolphins were fed. The animals' breathing frequency should be measured at various moments during the day. Another limitation is that this work was achieved in a single facility, the findings are thus only valid in this dolphinarium for this group of dolphins. More studies should be conducted in other dolphinaria with different age classes (e.g., our studied group was mainly composed of adults and only one calf) to compare the results because of the differences of time budget allocated to each activity that can be different depending on age. In addition, only social play intensity has been investigated but the intensity of solitary play should also be studied more extensively to investigate the relationship between play and welfare. Another factor that could potentially have influenced the result is the fact that dolphins engage in synchronous breathing (Hastie, Wilson, Tufft, \& Thompson, 2003; Sakai, Morisaka, Kogi, Hishii, \& Kohshima, 2010), so further studies should include this parameter. In addition to breathing rate, it would be beneficial to sample other respiratory parameters such as the VO2 to better describe the energy budget during each activity.

\section{Breathing Rate: An Ambiguous Parameter}

An increase in breathing rate could reveal a stress state in animals (Broom \& Johnson, 1993) but no correlation between respiration rates and blood cortisol concentration has been found in cetaceans (Eskesen et al., 2009). In free ranging fin whales, breathing rate varies depending on numerous external stimuli such as the proximity of vessels and the feeding behavior that increase the animal breathing rate (López et al., 2000). Our results show that social interactions that are known to be essential for bottlenose dolphins (Mann et al., 2000) significantly increased breathing rate. This result argues in favor of the use of social behaviors to evaluate welfare in these animals, where activities such as social play and agonistic behaviors could reveal a stressful or excitement state in the individuals. Here, social play seemed to be more exciting for the dolphins than solitary play and an increase in the intensity of play was linked to an increase in the dolphins' breathing rate. However, agonistic behaviors were also linked to an increase in breathing rate. In other words, increases in breathing rate can be signs of positive or negative excitement (Dawson, 1991). Some precautions need to be taken because the difference between excitation and stress is hard to find. For instance, social play in dolphins could be pleasurable (Kuczaj \& Eskelinen, 2014) and exciting, but can also escalate into dangerous activity (Herzing, 1996; Kuczaj \& Eskelinen, 2014), whereas agonistic behaviors could be stressful (Clark et al., 2006; St. Aubin \& Dierauf, 2001; Waples \& Gales, 2002). These findings need to be further investigated because of the potential consequences for the environmental enrichment and management of captive cetaceans. Moreover, ethological studies on dolphins should be conducted by scientists familiar with this species in order to avoid as much as possible misinterpretations of the animals' behaviors. As previously described, social contexts can be difficult to describe (e.g., rough social play and agonistic behavior, Johnson \& Norris, 1986).

In conclusion, this study confirmed that breathing rate in dolphins is linked to their age class and to the behaviors they simultaneously display, but not to the individual's sex. The fact that agonistic behaviors, social play, socio-sexual behaviors and solitary play engender an increase in breathing rate leads us to think that these behaviors might reflect an excitation (positive or negative) in the animals. Breathing rates were higher during social play and agonistic interactions than during solitary play, and this finding confirms that such social behaviors could potentially be used to evaluate captive dolphins' welfare. More studies are needed to validate this hypothesis and other physiological measurements would contribute to further investigate dolphins' social behaviors and specifically social play and its link with welfare. This study also highlights the ambivalence of breathing frequency, which increases when animals are positively or negatively excited. More studies are mandatory to understand the link between breathing rate and welfare. Other physiological parameters should be measured for each of these behaviors to assess the internal state of the dolphins when engaged in it. 


\section{Acknowledgements}

Many thanks to B. Mercera, the curator of the dolphinarium. The Parc Asterix animal care team: B. Mercera, S. Lecki, C. Levy, D. Mallet, J. Serrano, F. Besnoyoi J. Gout, D. Vergon and S. Torresan helped collecting the breathing rates. Pr. H. G. Rödel was a great help for data analysis and Chris Stokes, English native speaker, checked the manuscript.

\section{References}

Armstrong, A. J., \& Siegfried, W. R. (1991). Consumption of Antarctic krill by minke whales. Antarctic Science, 3, $13-18$.

Ax, A. F. (1953). The physiological differentiation between fear and anger in humans. Psychosomatic Medicine, 15, 433-442.

Bel'kovich, V. M., Lvanova, E. E., Kozarovitasky, L. B., Novikova, E. V., \& Kharitonov, S.P. (1991). Dolphin play behaviour in the open sea. In K. Pryor \& K. S. Norris (Eds.), Dolphin societies: Discoveries and puzzles (pp. 67-77). California: University of California Press.

Bianca, W. (1958). The relation between respiratory rate and heart rate in the calf subjected to severe heat stress. The Journal of Agricultural Science, 51, 321-324.

Blix, A. S., \& Folkow, L. P. (1995). Daily energy expenditure in free living minke whales. Acta Physiologica Scandinavia, 153, 61-66.

Broom, D. M., \& Johnson, K. G. (1993). Stress and animal welfare. London; Melbourne: Chapman and Hall.

Brown-Brandl, T., Nienaber, J. A., \& Turner, L. W. (1998). Acute heat stress effects on heat production and respiration rate in swine. Transactions of the ASAE, 41, 789-793.

Christiansen, F., Rasmussen, M. H., \& Lusseau, D. (2014). Inferring energy expenditure from respiration rates in minke whales to measure the effects of whale watching boat interactions. Journal of Experimental Marine Biology and Ecology, 459, 96-104.

Clark, L. S., Cowan, D. F., \& Pfeiffer, D. C. (2006). Morphological changes in the Atlantic bottlenose dolphin Tursiops truncatus, adrenal gland associated with chronic stress. Journal of Comparative Pathology, 135, 208-216.

Clemente, C. D., \& Lindsley, D. B. (1965, November). Aggression and defence: Neural mechanisms and social patterns. Proceedings of the 5th Conference on Brain Function, Sponsored by the Brain Research Institute, University of California Los Angeles.

Connor, R. C., \& Krützen, M. (2015). Male dolphin alliances in Shark Bay: Changing perspectives in a 30-year study. Animal Behaviour, 103, 223-235.

Connor, R. C., Smolker, R. A., \& Richards, A. F. (1992). Two levels of alliance formation among male bottlenose dolphins Tursiops sp. Proceedings of the National Academy of Sciences, 89, 987-990.

Costa, D. P., LeBoeuf, B. J., Huntley, A. C., \& Oritz, C. L. (1986). The energetics of lactation in the Northern elephant seal, Mirounga angustirostris. Journal of Zoology, 209, 21-33.

Dawson, S. M. (1991). Clicks and communication: The behavioural and social contexts of Hector's dolphin vocalizations. Ethology, 88, 265-276.

Dolar, M. L., Suarez, P., Ponganis, P. J., \& Kooyman, G. L. (1999). Myoglobin in pelagic small cetaceans. Journal of Experimental Biology, 202, 227-236.

Eskesen, I. G., Teilmann, J., Geertsen, B. M., Desportes, G., Riget, F., Dietz, R., \& Siebert, U. (2009). Stress level in wild harbour porpoises Phocoena phocoena during satellite tagging measured by respiration, heart rate and cortisol. Journal of the Marine Biological Association of the United Kingdom, 89, 885-892.

Eskesen, I. G., Teilmann, J., Geertsen, B. M., Desportes, G., Rigét, F., Dietz, R., Larsen, F., \& Siebert, U. (2009) Stress level in wild harbor porpoises (Phocoena phocoena) during satellite tagging measured by respiration, heart rate and cortisol. Journal of the Marine Biological Association of the United Kingdom, $89,885-892$.

Fahlman, A., Loring, S. H., Levine, G., Rocho-Levine, J., Austin, T., \& Brodsky, M. (2015). Lung mechanics and pulmonary function testing in cetaceans. Journal of Experimental Biology, 218, 2030-2038.

Fahlman, A., van der Hoop, J., Moore, M. J., Levine, G., Rocho-Levine, J., \& Brodsky, M. (2016). Estimating energetics in cetaceans from respiratory frequency: Why we need to understand physiology. Biology Open, 5, 436-442.

Fedak, M. A., \& Anderson, S. S. (1982). The energetics of lactation: Accurate measurements from a large wild 
mammal, the grey seal Halichoerus grypus. Journal of Zoology, 198, 473-479.

Folkow, L. P., \& Blix, A. S. (1992). Metabolic rates of minke whales Balaenoptera acutorostrata in cold water. Acta Physiologica Scandinavia, 146, 141-150.

Gaughan, J. B., Holt, S. M., Hahn, G. L., Mader, T. L., \& Eigenberg, R. A. (2000). Respiration rate — Is it a good measure of heat stress in cattle? Journal of Animal Science, 13, 329-332.

George, E. M., \& Noonan, M. (2014). Respiration rates in captive beluga whales (Delphinapterus leucas): Effects of season, sex, age, and body size. Aquatic Mammals, 40, 350-356.

Hastie, G. D., Wilson, B., Tufft, L. H., \& Thompson, P. M. (2003). Bottlenose dolphins increase breathing synchrony in response to boat traffic. Marine Mammal Science, 19, 74-84.

Herzing, D. (1996). Vocalizations and associated underwater behavior of free-ranging Atlantic spotted dolphins, Stenella frontalis and bottlenose dolphins, Tursiops truncatus. Aquatic Mammals, 22, 61-79.

Holm, S. (1979). A simple sequential rejective multiple test procedure. Scandinavian Journal of Statistics, 6, 65-70.

Irving, L., Scholander, P. F., \& Grinnell, S. W. (1940). Respiratory metabolism of the porpoise. Science, 91, 455.

Irving, L., Scholander, P. F., \& Grinnell, S. W. (1941). The respiration of the porpoise, Tursiops truncatus. Journal of Cellular and Comparative Physiology, 17, 145-168.

Johnson, C. M., \& Norris, K. S. (1986). Delphinid social organization and social behavior. In R. J. Schusterman, J. A. Thomas, \& F. G. Wood (Eds.), Dolphin cognition and behavior: A comparative approach (pp. 335-346) Hillsdale, NJ: Erlbaum.

Kooyman, G. L., Kerem, D. H., Campbell, W. B., \& Wright, J. J. (1971). Pulmonary function in freely diving Weddell seals, Leptonychotes weddelli. Respiration Physiology, 12, 271-282.

Kuczaj, S. A., \& Eskelinen, H. C. (2014). Why do dolphins play? Animal Behaviour and Cognition, 12, 113-127.

Kuczaj, S. A., Makecha, R., Trone, M., Paulos, R. D., \& Ramos, J.A. (2006). Role of peers in cultural innovation and cultural transmission: Evidence from the play of dolphin calves. International Journal of Comparative Psychology, 19, 253-277.

Lafortuna, C. L., Jahoda, M., Azzellino, A., Saibene, F., \& Colombini, A. (2003). Locomotor behaviours and respiratory pattern of the Mediterranean fin whale Balaenoptera physalus. European Journal of Applied Physiology, 90, 287-295.

López, D. B., Mussi, B., Miragliuolo, A., Chiota, D., \& Valerio, L. (2000). Respiration patterns of fin whales off Ischia, Archipelago Campano, Mediterranean Sea. European Research on Cetaceans, 14, 125-129.

Mann J. (1999). Behavioral sampling methods for cetacean: A review and critique. Marine Mammal Science, 15, $102-122$.

Mann J. (2006). Establishing trust: Socio-sexual behaviour and the development of male-male bonds among Indian Ocean bottlenose dolphins. In V. Sommer \& P. L. Vasey (Eds.), Homosexual Behaviour in Animals (pp. 107-130). Cambridge, UK: Cambridge University Press.

Mann, J., Connor, R. C., Tyack, P. L., \& Whitehead, H. (2000). Cetacean societies: Field studies of dolphins and whales. Chicago: University of Chicago Press.

Mann, J., \& Smuts, B. (1999). Behavioral development in wild bottlenose dolphin newborns Tursiops sp. Behaviour, 136, 529-566.

Marino, L., Sol D., Toren, K., \& Lefebvre, L. (2006). Does diving limit brain size in cetaceans? Marine Mammal Science, 22, 413-425.

McBride, A. F., \& Hebb, D. O. (1948). Behavior of the captive bottle-nose dolphin, Tursiops truncatus. Journal of Comparative Physiology and Psychology, 41, 111-123.

Miller, P. J. O., Shapiro, A. D., \& Deecke, V. B. (2010). The diving behaviour of mammal-eating killer whales Orcinus orca: Variations with ecological not physiological factors. Canadian Journal of Zoology, 88, $1103-1112$.

Moderi, A. (2007). The development of respiratory and diving ability in the bottlenose dolphin calves of Shark Bay, Western Australia (unpublished honors thesis). Georgetown University, Washington DC.

Mortola, J. P., \& Limoges, M. (2006). Resting breathing frequency in aquatic mammals: A comparative analysis with terrestrial species. Respiratory Physiology \& Neurobiology, 154, 500-514.

Noren, S. R., Biedenbach, G., \& Edwards, E. F. (2006). Ontogeny of swim performance and mechanics in bottlenose dolphins Tursiops truncatus. Journal of Experimental Biology, 209, 4724-4731.

Noren, S. R., Iverson, S. J., \& Boness, D. J. (2005). Development of the blood and muscle oxygen stores in gray seals Halichoerus grypus: Implications for juvenile diving capacity and the necessity of a terrestrial postweaning fast. Physiological and Biochemical Zoology, 78, 482-490.

Noren, S. R., Lacave, G., Wells, R. S., \& Williams, T. M. (2002). The development of blood oxygen stores in bottlenose dolphins Tursiops truncatus: Implications for diving capacity. Journal of Zoology, 258, 105- 
113.

Noren, S. R., Redfern, J. V., \& Edwards, E. F. (2011). Pregnancy is a drag: Hydrodynamics, kinematics and performance in pre- and post-parturition bottlenose dolphins Tursiops truncatus. Journal of Experimental Biology, 214, 4151-4159.

Noren, S. R., \& Williams, T. M. (2000). Body size and skeletal muscle myoglobin of cetaceans: Adaptations for maximizing dive duration. Comparative biochemistry and physiology A, 126, 181-191.

Noren, S. R., Williams, T. M., Pabst, D. A., Mclellan, W. A., \& Dearolf, J. L. (2001). The development of diving in marine endotherms: Preparing the skeletal muscles of dolphins, penguins, and seals for activity during submergence. Journal of Comparative Physiology B, 171, 127-134.

Noren, S. R., Williams, T. M., Ramirez, K., Boehm, J., Glenn, M., \& Cornell, L. (2012). Changes in partial pressures of respiratory gases during submerged voluntary breath hold across odontocetes: Is body mass important? Journal of Comparative Physiology B, 182, 299-309.

Nowacek, S. M., Wells, R. S., \& Solow, A. R. (2001). Short-term effects of boat traffic on bottlenose dolphins, Tursiops truncatus, in Sarasota Bay, Florida. Marine Mammal Science, 17, 673-688.

Overstrom, N. A. (1983). Association between burst-pulsed sounds and aggressive behavior in captive Atlantic bottlenosed dolphins Tursiops truncatus. Zoo Biology, 2, 93-103.

Pace, D. S. (2000). Fluke-made bubble rings as toys in bottlenose dolphin calves Tursiops truncatus. Aquatic Mammals, 26, 57-64.

Paulos, R. D., Trone, M., \& Kuczaj, S. (2010). Play in wild and captive cetaceans. International Journal of Comparative Psychology, 23, 701-722.

Read A. J., Wells R. S., Hohn A. A., \& Scott M. D. (1993). Patterns of growth in wild bottlenose dolphins, Tursiops truncatus. Journal of Zoology, 231, 107-123.

Reed, J. Z., Chambers, C., Hunter, C. J., Lockyer, C., Kastelein, R., Fedak, M. A., \& Boutilier, R. G. (2000). Gas exchange and heart rate in the harbor porpoise, Phocoena phocoena. Journal of Comparative Physiology B, $170,1-10$.

Roos, M. M., Wu, G. M., \& Miller, P. J. (2016). The significance of respiration timing in the energetics estimates of free-ranging killer whales Orcinus orca. Journal of Experimental Biology, 219, 2066-2077.

Sakai, M., Morisaka, T., Kogi, K., Hishii, T., \& Kohshima, S. (2010). Fine-scale analysis of synchronous breathing in wild Indo-Pacific bottlenose dolphins Tursiops aduncus. Behavioral Processes, 83, 48-53.

Sauer, E. F. (1963). Courtship and copulation of the gray whale in the Bering Sea at St. Lawrence Island, Alaska. Psychologische Forschung, 27, 157-174.

Serres, A., \& Delfour, F. (2017). Environmental changes and anthropogenic factors modulate social play in captive bottlenose dolphins Tursiops truncatus. Zoo Biology, 36, 1-13.

Shane, S. H., Wells, R. S., \& Würsig, B. (1986). Ecology, behavior and social organization of the bottlenose dolphin: A review. Marine Mammal Science, 2, 34-63.

Southall, B. L., Bowles, A. E., Ellison, W. T., Finneran, J. J., Gentry, R. L., Greene Jr, C. R., \& Richardson, W. J. (2007). Structure of the noise exposure criteria. Aquatic Mammals, 33, 427.

Sparling, C. E., \& Fedak, M. A. (2004). Metabolic rates of captive grey seals during voluntary diving. Journal of Experimental Biology, 207, 1615-1624.

Sparling, C. E., Fedak, M. A., \& Thompson, D. (2007). Eat now, pay later? Evidence of deferred food-processing costs in diving seals. Biology Letters, 3, 94-98.

Spinka, M., Newberry, R. C., \& Bekoff, M. (2001). Mammalian play: Training for the unexpected. Quaterly Review of Biology, 76, 141-168.

Srikandakumar, A., \& Johnson, E. (2004). Effect of heat stress on milk production, rectal temperature, respiratory rate and blood chemistry in Holstein, Jersey and Australian Milking Zebu Cows. Tropical Animal Health and Production, 36, 685-692.

St. Aubin, D. J., \& Dierauf, L. A. (2001). Stress and marine mammals. In L. A. Dierauf \& F. M. D. Gulland (Eds.), CRC handbook of marine mammal medicine 2nd ed., Boca Raton, FL: CRC Press.

Sumich, J. L. (1983). Swimming velocities, breathing patterns, and estimated costs of locomotion in migrating gray whales, Eschrichtius robustus. Canadian Journal of Zoology, 61, 647-652.

Sumich, J. L. (2001). Direct and indirect measures of oxygen extraction, tidal lung volumes and respiratory rates in a rehabilitating gray whale calf. Aquatic Mammals, 27, 279-283.

Thomas, P. O., \& Taber, S. M. (1984). Mother-infant interaction and behavioral development in southern right whales, Eubalaena australis. Behaviour, 88, 42-60.

Vicino, G. A., \& Marcacci, E. F. (2015). Intensity of play behavior as a potential measure of welfare: A novel method for quantifying the integrated intensity of behavior in African elephants. Zoo Biology, 34, 492-496. 
Wahrenbrock, E. A., Maruschak, G. F., Elsner, R., \& Kenney, D. W. (1974). Respiration and metabolism in two baleen whale calves. Marine Fisheries Review, 36, 3-8.

Waples, K. A., \& Gales, N. J. (2002). Evaluating and minimising social stress in the care of captive bottlenose dolphins Tursiops aduncus. Zoo Biology, 21, 5-26.

Webster, J. (2005). Challenge and response. In J. K. Kirkwood, R. C. Hubrecht, \& E. A. Roberts (Eds), Animal welfare limping towards eden (pp. 43-45). Oxford: Blackwell Publishing.

Williams, T. M., Friedl, W. A., \& Haun, J. E. (1993). The physiology of bottlenose dolphins Tursiops truncatus: Heart rate, metabolic rate and plasma lactate concentration during exercise. Journal of Experimental Biology, 179, 31-46.

Williams, T. M., Haun, J., Davis, R. W., Fuiman, L. A., \& Kohin, S. (2001). A killer appetite: Metabolic consequences of carnivory in marine mammals. Comparative Biochemistry and Physiology A, 129, 785796.

Williams, T. M., Haun, J. E., \& Friedl, W. A. (1999). The diving physiology of bottlenose dolphins Tursiops truncatus. I. Balancing the demands of exercise for energy conservation at depth. Journal of Experimental Biology, 202, 2739-2748.

Williams, R., \& Noren, D. P. (2009). Swimming speed, respiration rate, and estimated cost of transport in adult killer whales. Marine Mammal Science, 25, 327-350.

Würsig, B., \& Würsig, M. (1979). Behaviour and ecology of the bottlenose dolphin, Tursiops truncatus, in the South Atlantic. Fishery Bulletin, 77, 399-413.

Würsig, B., Dorsey, E. M., Richardson, W. J., \& Wells, R. S. (1989). Feeding, aerial and play behaviour of the bowhead whale, Balaena mysticetus, summering in the Beaufort Sea. Aquatic Mammals, 15, 27-37.

Yazdi, P., Kilian, A., \& Culik B. M. (1999). Energy expenditure of swimming bottlenose dolphins Tursiops truncatus. Marine Biology, 134, 601-607. 